\title{
A Non-Atherogenic and Atherogenic Lipoprotein Profile in Individuals with Dyslipoproteinemia
}

\author{
Stanislav Oravec, Johannes Mikl, Kristina Gruber and Elisabeth Dostal
}

Additional information is available at the end of the chapter

http://dx.doi.org/10.5772/46067

\section{Introduction}

The 1985 Nobel Prize in Medicine was awarded to American lipidologists Goldstein and Brown for their work in identifying the role of the LDL receptor pathway in lipoprotein metabolism and in maintaining the homeostasis of blood cholesterol (Goldstein \& Brown 1985).

The discovery of the LDL receptor and an understanding of its role in lipid metabolism in health and illness were a milestone in research into metabolic disorders in lipids. At the same time, some other successes in lipoprotein research were also reported: a new understanding of the role of oxidized LDL in atherosclerosis pathogenesis (Steinberg 1987, Witztum \& Steinberg 1991); an update of the Ross theory on atherosclerosis genesis (Ross 1986); studies with hypolipidemics; a cholestyramine study, the Coronary Drug Project with niacin, and the Helsinki Heart Study with gemfibrosil. The next two decades was devoted to the effort to create sophisticated criteria for determining risk groups in populations, developing a consensus about cholesterol, and adopting pharmacological uniformity to achieve so-called target lipid values in at-risk individuals with dyslipidemia. The welldefined criteria as a result of these efforts gave hope to at-risk individuals for longer-term survival without ischemic vascular accidents (Canner et al. 1986, Frick et al. 1987, Expert panel 2001).

Generally, it was confirmed that hypercholesterolemia represents a risk factor for the development of cardiovascular diseases. In addition to arterial hypertension and nicotine abuse, hypercholesterolemia is considered one of three cardinal risk factors.

Cholesterol in plasma is transported by a sophisticated lipoprotein complex system and is also an active part of this lipoprotein system. Different parts of the lipoprotein system are called lipoprotein families. Every lipoprotein family transports different concentrations of 
cholesterol in blood plasma, but the major conveyor of cholesterol in plasma is the family of Low Density Lipoproteins, i.e., the LDL family. LDL is considered an atherogenic part of the lipoprotein system (Kwiterovich 2002a, 2002b).

LDL transports a major cholesterol load from the liver to the peripheral cells of the body. Under conditions of impaired LDL catabolism in the periphery, LDL particles persist in the circulation, their physical-chemical characteristics are modified, and the physiological pathway of LDL degradation - via LDL receptors - fails. The consequence of this sequence of events is the formation of an alternative metabolic pathway of LDL degradation through scavenger receptors and the formation of cholesterol deposits in the subendothelial space of the arterial wall. In this way, the process of atherogenesis and atherothrombosis begins; and LDL particles play a crucial role at the beginning and in the development of this injury process in the vessel walls (Berneis \& Krauss 2002, Haffner 2006, Fruchart et al. 2008).

LDL-cholesterol became a criterion for the degree of atherogenic risk for the development of atherothrombosis. A high LDL-cholesterol concentration in plasma correlates positively with the premature onset of cardiovascular diseases, and is considered a strong cardiovascular risk factor. From this point of view, the aim of treatment of hypercholesterolemia, in secondary as well as in primary prevention, is the reduction of LDL concentration in plasma and a lowering of the cholesterol level to the "target reference values" (Expert panel 2001, Backers 2005).

However, in the last few decades, lipoprotein research has focused on the phenomenon of atherogenic and non-atherogenic lipoproteins, atherogenic and non-atherogenic lipoprotein profiles, and on the phenotype A vs. phenotype B characterization (Austin et al. 1990, Chait et al. 1993, Van et al. 2007). The traditional approach to hypercholesterolemia as an atherogenic risk factor for the development of degenerative diseases of the cardiovascular system became a target of criticism. Castelli published evidence that more than 75 percent of patients with an acute coronary syndrome or a myocardial infarction had normal plasma values of cholesterol, LDL cholesterol and/or HDL cholesterol (Castelli 1988, 1992, 1998). Thus, it was necessary to look for other risk factors in plasma, at levels that could cause an acute coronary event. An increased cholesterol level, as an universal explanation for the origin of atherogenesis, was no longer valid.

A reasonable explanation was found in atherogenic lipoprotein subpopulations, the presence of which in plasma, even in very low concentrations, could impair the integrity of the vessel wall and lead to endothelial dysfunction with its fatal consequences: formation of atherothrombotic plaques, acute myocardial infarction, stroke, and sudden death (Nichols \& Lundmann 2004, Rizzo \& Berneis 2006, Shoji et al. 2009, Zhao et al. 2009).

Those laboratory analysis methods became an essential contribution to the identification of atherogenic lipoprotein entities, which simplified the analysis and quantification of the atherogenic lipoprotein subfractions. Gradient gel elecrophoretic separation of LDL and HDL subclasses or proton nuclear magnetic resonance spectroscopy were the methods of choice for the analysis of these entities (Rainwater et al. 1997, Alabakovska et al. 2002, Otvos et al. 2003). 
Recently, electrophoresis of plasma lipoproteins on the polyacrylamide gel (PAG) Lipoprint LDL System is one of several diagnostic analytical methods for the identification and quantitative evaluation of lipoprotein subfractions, i.e., the atherogenic and non-atherogenic lipoproteins (Hoefner et al. 2001).

The LDL System has become a staple in routine laboratory analysis and in the diagnosis of lipoprotein metabolism disorders, and has also been recommended by the FDA for human medicine. Lipoprint LDL enables the analysis of 12 lipoprotein subfractions: VLDL; IDL1; IDL2; IDL3; LDL1; LDL2; LDL 3-7; HDL; and determines an atherogenic lipoprotein profile phenotype $\mathrm{B}$ versus a non-atherogenic lipoprotein profile phenotype A.

Atherogenic lipoprotein profiles are characterized by a predominance of atherogenic lipoproteins, namely very low density (VLDL), intermediate density IDL1, and IDL2, and particularly by the presence of small dense lipoproteins with low density (LDL). Profiles identify highly atherogenic LDL subfractions that form the LDL 3-7 fractions (Tab.1). These subfractions are smaller, with a diameter $<26.5 \mathrm{~nm}$ (265 Angström) and they float within a density range of $1.048-1.065 \mathrm{~g} / \mathrm{ml}$, i.e., a higher density than LDL1 and LDL2. On the PAG they are detected as subtle bands on the anodic end of the gel right behind HDL that migrate to the head of separated lipoproteins.

\begin{tabular}{|c|c|}
\hline $\begin{array}{l}\text { Small dense } \\
\text { Packard } 200\end{array}$ & $\begin{array}{l}\text { are highly atherogenic for ((Berneis\&Krauss 2002, Lamarche et al. 1999, } \\
\text { mena et al. 2004): }\end{array}$ \\
\hline $\begin{array}{l}\text { *low recogn } \\
\text { (configurati }\end{array}$ & $\begin{array}{l}\text { by LDL-receptors } \\
\text { terations Apo B ) } \rightarrow\end{array}$ \\
\hline *enhanced a & Ide for oxidation and acetylation $\rightarrow$ \\
\hline *Oxid-LDL & $\begin{array}{l}\rightarrow \text { release of pro-inflammatory cytokines } \\
\rightarrow \text { muscle cell apoptosis }\end{array}$ \\
\hline${ }^{*}$ Oxid-LDL & $\begin{array}{l}\rightarrow \text { release of metalloproteinase } \\
\rightarrow \text { collagen degradation }\end{array}$ \\
\hline${ }^{*}$ Oxid-LDL & $\begin{array}{l}\rightarrow \text { enhanced aptitude for trapping by macrophages (scavenger-receptors) } \\
\rightarrow \text { stimulation of foam cell formation }\end{array}$ \\
\hline
\end{tabular}

Table 1.

On the basis of lipoprotein separation by the Lipoprint LDL System, a non-atherogenic normolipidemia, an atherogenic normolipidemia, a non-atherogenic hyperbetalipoproteinemia and an atherogenic hyperlipoproteinemia can be characterized (Oravec 2006a, 2006b, 2007a, 2007b).

Two of these are identified as new lipoprotein profiles with high clinical significance: an atherogenic normolipidemia and a non-atherogenic hyper-betalipoproteinemia LDL1,2.

A non-atherogenic hyperbetalipoproteinemia LDL1,2 involves individuals with a high concentration of plasma cholesterol, predominantly transported by LDL1 and LDL2 subfractions. However, these individuals are at low risk for a cardiovascular event based on 
cardiologic and angiologic examimation results, and have familial history negative for cardiovascular diseases.

Conversely, an atherogenic normolipidemia was identified in a group of individuals with normal cholesterol and triglyceride concentrations in plasma, who had a high concentration of strongly atherogenic small dense LDL in the lipoprotein profile. These individuals could be at higher risk for a cardiovascular event despite normolipidemia.

In our clinical study, we characterized hypercholesterolemic individuals with untreated hypercholesterolemia, who had a non-atherogenic hyperbetalipoproteinemia, as well as normolipemic individuals who were currently without clinical or laboratory signs of damage to the cardiovascular system, but who, nevertheless, had an atherogenic lipoprotein profile. All these subjects underwent a medical examination to identify the extent of the arterial vessel damages caused by hypercholesterolemia, or dyslipidemia.

\section{Patients and methods}

The hypercholesterolemic individuals with untreated hypercholesterolemia were tested by Lipoprint LDL analysis. In this group of hypercholesterolemic subjects, 145 individuals with a non-atherogenic lipoprotein profile were identified.

Of the total number, 15 individuals were under 40 years of age without clinically apparent impairment and no laboratory signs of cardiovascular disease. These subjects formed one subgroup of younger people (34 years +- 5 years). The subgroup of younger subjects was separated from the older individuals with hypercholesterolemia because a separate analysis of the older subjects with hypercholesterolemia was performed to confirm that undamaged vessels in older individuals persist even into old age, and that diagnosed hypercholesterolemia does not cause an atherogenic impairment in the vessels. The subgroup of older subjects consisted of 130 individuals (32 males, $57+-11$ years of age; and 98 females, $62+-9$ years of age).

The medical examination, which included a physical examination, blood pressure, and ECG examination, bicycle stress test, echocardiography, and duplex ultrasound examination of the carotid arteries, confirmed that there was no impairment of the cardiovascular system. Only mild signs of clinically irrelevant aortic valve sclerosis were found in the subgroup of older subjects.

Individuals with hyperglycemia, diabetics, and those individuals who were being treated with lipid-lowering drugs were excluded from the study.

The control group consisted of 165 normolipidemic volunteers, all nonsmokers, who had no clinically apparent impairment, or laboratory signs of cardiovascular disease. Volunteers were recruited from medical students at the medical facility. The average age of the subjects was $21.5 \pm 2.5$ years, and the group involved 65 males and 100 females. All subjects gave written, informed consent, and the study was approved by the local ethics committee. 
A blood sample from the antecubital vein was collected in the morning after a 12-hour fasting period. EDTA-K 2 plasma was obtained and the concentration of total cholesterol and triglycerides in plasma was analyzed, using an enzymatic CHOD PAP method (Roche Diagnostics, Germany).

The quantitative analysis of lipoprotein families and lipoprotein subfractions included: VLDL; IDL1; IDL2; IDL3; LDL1; LDL2; LDL3-7; and HDL. A non-atherogenic lipoprotein profile, phenotype $\mathrm{A}$, versus an atherogenic lipoprotein profile, phenotype $\mathrm{B}$, was determined using the Lipoprint LDL System (Quantimetrix Corp., USA; (Hoefner et al. 2001). The analysis of HDL subclasses, with their subpopulations, including large HDL-, intermediate HDL-, and small HDL- subclasses in plasma, was also performed using the Lipoprint HDL System (Morais et al. 2003).

The Score of the Anti-Atherogenic Risk (SAAR) was calculated as the ratio between nonatherogenic and atherogenic lipoproteins in plasma (Oravec 2007a). SAAR values over 10.8 represented a non-atherogenic lipoprotein profile, whereas values under 9.8 represented an atherogenic lipoprotein profile. The cut-off values for a non-atherogenic lipoprotein profile and an atherogenic lipoprotein profile were calculated from the results of 940 Lipoprint LDL analyses. Using the Quantimetrix Lipoprint LDL system interpretation, all 940 individuals were examined (general group of subjects) and tested for the occurrence of atherogenic and non-atherogenic lipoprotein profiles, and were then divided into the two subgroups of subjects with an LDL profile:

- Indicative of Type A, i.e., a non-atherogenic lipoprotein profile phenotype A

- Not indicative of Type A, i.e., an atherogenic lipoprotein profile, phenotype B (Hoefner et al. 2001).

For practical interpretation of the analysed lipoprotein profiles using the Lipoprint LDL System, for the non-atherogenic lipoprotein phenotype A, the subtypes 1a, 1b, 2a, 2b, 3, and 4 were introduced, because of the large profile heterogeneity in the non-atherogenic lipoprotein profile phenotype A. With regard to the atherogenic lipoprotein phenotype B, only subtype 5 and subtype 6 were introduced. (Oravec 2007b). (Tab.2)

Statistical evaluation of obtained values was performed by an unpaired student's t-test. The level of significance was set at $\mathrm{p}<0.05$.

\section{Results}

The subjects with a non-atherogenic hypercholesterolemia had a significantly increased concentration of total cholesterol and lipoprotein parameters ( $\mathrm{p}<0.0001)$, except for LDL 3-7 subfractions (small dense LDL), which were significantly lower $(\mathrm{p}<0.0001)$, compared to the control group (Tab.3). The highest increase of concentrations was found for total cholesterol, LDL cholesterol, HDL cholesterol, IDL3, and LDL1 subfractions. The concentration of LDL1 exceeded the LDL1 concentration in the control group by more than 88 percent. The LDL1 concentration in the younger hypercholesterolemic subjects reached $1.84 \mathrm{mmol} / \mathrm{l}$, i.e., more 
than twice, comparing to $0.89 \mathrm{mmol} / 1$ in the control group. (Tab.3, Tab.5). The rise of LDL2 concentration (32 percent in younger hypercholesterolemic subjects), did not match the increase in LDL1 concentrations (Tab.3 - Tab.6).

A. Non-atherogenic lipoprotein profile, phenotype A ......

1a. Subtype: Non-atherogenic lipoprotein profile phenotype A.....

Atherogenic lipoproteins absent

LDL cholesterol normal

1b. Subtype: Non-atherogenic lipoprotein profile phenotype A.....

$10 \%$

Atherogenic lipoproteins absent

LDL cholesterol elevated

2a. Subtype: Non-atherogenic lipoprotein profile phenotype A......

$12 \%$

Atherogenic lipoproteins present in traces

LDL cholesterol normal

2b. Subtype: Non-atherogenic lipoprotein profile phenotype A...

Atherogenic lipoproteins present in traces

LDL cholesterol elevated

3. Subtype: Non-atherogenic lipoprotein profile phenotype A.......

Atherogenic lipoproteins present

LDL cholesterol normal

4. Subtype: Non-atherogenic lipoprotein profile phenotype A .......

Atherogenic lipoproteins present

LDL cholesterol elevated

B. Atherogenic lipoprotein profile phenotype B

5. Subtype: Atherogenic lipoprotein profile phenotype B

Atherogenic lipoproteins present

LDL cholesterol normal

6. Subtype: Atherogenic lipoprotein profile phenotype B

Atherogenic lipoproteins present

LDL cholesterol elevated

An atherogenic lipoprotein profile was identified in $41 \%$ of examined individuals in a general group of subjects $(n=$ 940), (Oravec 2007b).

Table 2. Incidence rate of non-atherogenic vs. atherogenic lipoprotein subtypes in a general group of subjects $(n=940)$ 
T-Chol

$(\mathrm{mmol} / \mathrm{l} \pm \mathrm{SD})$

TAG VLDL IDL1 IDL2 IDL3 LDL1 LDL2 LDL3-7 T-LDL HDL SAAR

\begin{tabular}{lcccccccccccc}
\hline Control & 4.31 & 1.16 & 0.62 & 0.39 & 0.28 & 0.33 & 0.89 & 0.41 & 0.04 & 2.34 & 1.33 & 36.1 \\
$\mathrm{n}=165$ & \pm 0.62 & \pm 0.39 & \pm 0.16 & \pm 0.16 & \pm 0.09 & \pm 0.12 & \pm 0.28 & \pm 0.21 & \pm 0.04 & \pm 0.54 & \pm 0.32 & \pm 20.6 \\
$\mathrm{H}-\beta \mathrm{LP}$ & 6.71 & 1.29 & 0.74 & 0.55 & 0.51 & 0.82 & 1.68 & 0.52 & 0.01 & 4.09 & 1.88 & 76.0 \\
$\mathrm{n}=145$ & \pm 0.90 & \pm 0.49 & \pm 0.21 & \pm 0.16 & \pm 0.12 & \pm 0.23 & \pm 0.36 & \pm 0.21 & \pm 0.01 & \pm 0.69 & \pm 0.46 & \pm 17.0
\end{tabular}

Control

vs. $\quad \mathrm{p}<$

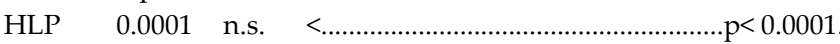

Legend: T-cholesterol: total cholesterol, T-LDL: total LDL-cholesterol, H- $\beta$ LP: hyperbetalipoproteinemia

Table 3. Plasma concentration of lipids, lipoproteins, and SAAR score in the group of hypercholesterolemic subjects vs. control normolipidemic subjects

T-Chol

$(\mathrm{mmol} / \mathrm{l} \pm \mathrm{SD})$

TAG VLDL IDL1 IDL2 IDL3 LDL1 LDL2 LDL3-7 T-LDL HDL SAAR

\begin{tabular}{lcccccccccccc}
\hline Control & 4.31 & 1.16 & 0.62 & 0.39 & 0.28 & 0.33 & 0.89 & 0.41 & 0.04 & 2.34 & 1.33 & 36.1 \\
$\mathrm{n}=165$ & 36.1 & \pm 0.39 & \pm 0.16 & \pm 0.16 & \pm 0.09 & \pm 0.12 & \pm 0.28 & \pm 0.21 & \pm 0.04 & \pm 0.54 & \pm 0.32 & \pm 20.6 \\
$\mathrm{H}-\beta \mathrm{LPs}$ & 6.73 & 1.30 & 0.73 & 0.55 & 0.52 & 0.80 & 1.67 & 0.52 & 0.01 & 4.08 & 1.93 & 76.5 \\
$\mathrm{n}=130$ & \pm 0.91 & \pm 0.48 & \pm 0.19 & \pm 0.16 & \pm 0.13 & \pm 0.23 & \pm 0.35 & \pm 0.22 & \pm 0.01 & \pm 0.69 & \pm 0.45 & \pm 18.1
\end{tabular}

Control

vs. $\quad \mathrm{p}<$

HLP 0.0001 n.s.

$. . \mathrm{p}<0.0001$

Legend: H- $\beta$ LPs : hyperbetalipoproteinemia subgroup of seniors

Table 4. Plasma concentration of lipids, lipoproteins, and SAAR score in the subgroup of older hypercholesterolemic subjects and controls

T-Chol

$(\mathrm{mmol} / \mathrm{l} \pm \mathrm{SD})$

TAG VLDL IDL1 IDL2 IDL3 LDL1 LDL2 LDL3-7 T-LDL HDL SAAR

\begin{tabular}{lcccccccccccc}
\hline Control & 4.31 & 1.16 & 0.62 & 0.39 & 0.28 & 0.33 & 0.89 & 0.41 & 0.04 & 2.34 & 1.33 & 36.1 \\
$\mathrm{n}=165$ & \pm 0.62 & \pm 0.39 & \pm 0.16 & \pm 0.16 & \pm 0.09 & \pm 0.12 & \pm 0.28 & \pm 0.21 & \pm 0.04 & \pm 0.54 & \pm 0.32 & \pm 20.6 \\
$\mathrm{H}-\beta \mathrm{LPjr}$ & 6.62 & 1.20 & 0.84 & 0.58 & 0.44 & 0.80 & 1.84 & 0.54 & 0.01 & 4.20 & 1.46 & 71.1 \\
$\mathrm{n}=15$ & \pm 0.80 & \pm 0.59 & \pm 0.28 & \pm 0.18 & \pm 0.01 & \pm 0.25 & \pm 0.42 & \pm 0.18 & \pm 0.01 & \pm 0.64 & \pm 0.23 & \pm 13.2
\end{tabular}

Control

vs. $\quad \mathrm{p}<\mathrm{p}<\mathrm{p}<$

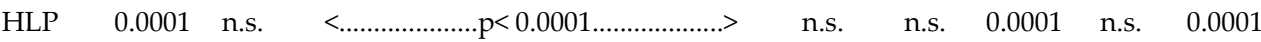

Legend: $\mathrm{H}-\beta \mathrm{LP} \mathrm{j} \mathrm{r}$ : hyperbetalipoproteinemia subgroup of younger hypercholesterolemic subjects

Table 5. Plasma concentration of lipids, lipoproteins, and SAAR-score in the subgroup of younger hypercholesterolemic subjects and controls 
T-Chol $(\mathrm{mmol} / 1 \pm \mathrm{SD})$

TAG VLDL IDL1 IDL2 IDL3 LDL1 LDL2 LDL3-7 T-LDL HDL SAAR

\begin{tabular}{|c|c|c|c|c|c|c|c|c|c|c|c|c|}
\hline $\begin{array}{l}\text { H- } \beta \text { LPjr } \\
n=15\end{array}$ & $\begin{array}{c}6.62 \\
\pm 0.80\end{array}$ & $\begin{array}{c}1.20 \\
\pm 0.59\end{array}$ & $\begin{array}{c}1.20 \\
\pm 0.28\end{array}$ & $\begin{array}{c}0.58 \\
\pm 0.18\end{array}$ & $\begin{array}{c}0.44 \\
\pm 0.01\end{array}$ & $\begin{array}{c}0.80 \\
\pm 0.25\end{array}$ & $\begin{array}{c}1.84 \\
\pm 0.42\end{array}$ & $\begin{array}{c}0.54 \\
\pm 0.18\end{array}$ & $\begin{array}{c}0.01 \\
\pm 0.01\end{array}$ & $\begin{array}{c}4.20 \\
\pm 0.64\end{array}$ & $\begin{array}{c}1.46 \\
\pm 0.23\end{array}$ & $\begin{array}{c}71.1 \\
\pm 13.2\end{array}$ \\
\hline H- $\beta$ LPs & 6.73 & 1.30 & 0.73 & 0.55 & 0.52 & 0.80 & 1.67 & 0.52 & 0.01 & 4.08 & 1.93 & 76.5 \\
\hline $\mathrm{n}=130$ & \pm 0.91 & \pm 0.48 & \pm 0.19 & \pm 0.16 & \pm 0.13 & \pm 0.23 & \pm 0.35 & \pm 0.22 & \pm 0.01 & \pm 0.69 & \pm 0.45 & \pm 18.1 \\
\hline
\end{tabular}

juniors v.s. seniors

Legend: H- $\beta$ LP jr.: Hyperlipoproteinemia subgroup of younger subjects H- $\beta$ LP s.: Hyperlipoproteinemia subgroup of older subjects

Table 6. Plasma concentration of lipids, lipoproteins, and SAAR-score in the subgroup of younger $(\mathrm{n}=15)$ versus older $(\mathrm{n}=130)$ hypercholesterolemic subjects

The lipid and lipoprotein parameters in younger and older hypercholesterolemic subjects were very similar, and the results were not statistically significantly different between the groups, except that HDL cholesterol in the older hypercholesterolemic individuals was statistically significant higher $(\mathrm{p}<0.001)$ compared to the control group (Tab.6). Results similar to those in older hypercholesterolemic subjects were obtained when the group of younger hypercholesterolemic subjects was compared to the control group (Tab.5), except for LDL2, LDL 3-7, and HDL lipoproteins, where the changes in the cholesterol concentrations - increased in LDL2- and decreased in LDL3-7 subfractions were not significant.

\begin{tabular}{lcccc} 
& $\begin{array}{c}\text { T-HDL } \\
\text { mmol/1 } \\
\pm \text { SD }\end{array}$ & HDL large & HDL intermediate & HDL small \\
\hline Control & 1.31 & 0.59 & 0.56 & 0.15 \\
$(\mathrm{n}=103)$ & \pm 0.29 & \pm 0.23 & \pm 0.10 & \pm 0.09 \\
H- $\beta$ LP & 1.51 & 0.70 & 0.65 & 0.15 \\
$(\mathrm{n}=110)$ & \pm 0.34 & \pm 0.46 & \pm 0.42 & \pm 0.12 \\
& $\mathrm{p}<0.0001$ & $\mathrm{p}<0.005$ & $\mathrm{p}<0.005$ & n.s. \\
\hline
\end{tabular}

Legend: T-HDL: total HDL

Table 7. Plasma concentration of HDL lipoprotein subclasses

Tab.7 shows the HDL-cholesterol concentration and HDL subclasses, analysed by the Lipoprint HDL System. The concentration of total HDL cholesterol (T-HDL) in the group of hypercholesterolemic subjects was significantly higher $(\mathrm{p}<0.0001)$, compared to the control group. There was an increased concentration of both HDL subclasses, i.e. the HDL large subclass $(\mathrm{p}<0.005)$ and the HDL intermediate subclass $(\mathrm{p}<0.005)$ in the hypercholesterolemia subjects. The difference in the concentration of the HDL small subclass between hypercholesterolemic subjects and the control group was not confirmed. 


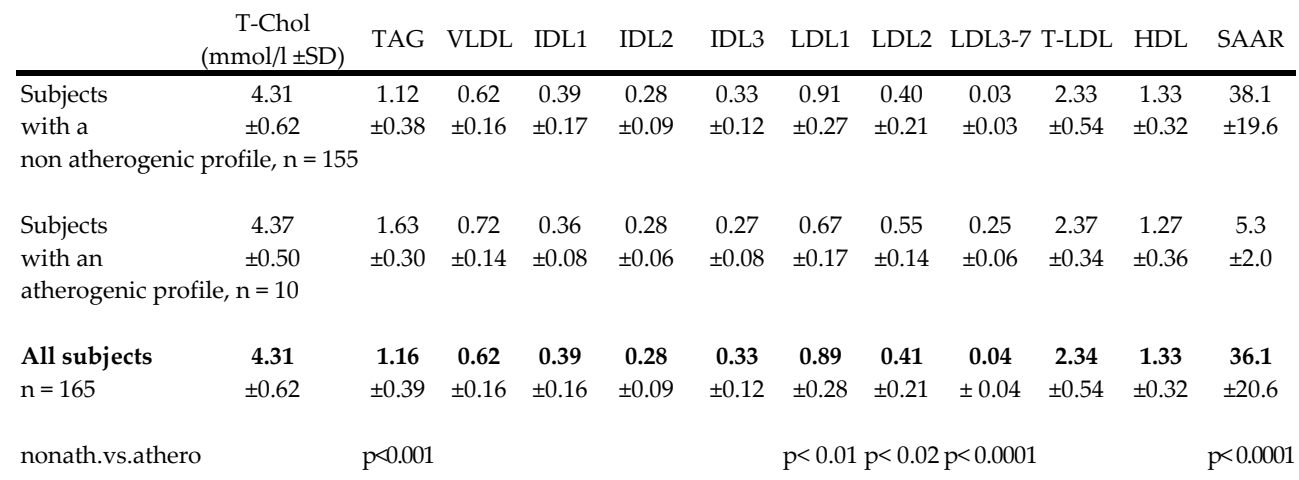

Table 8. Plasma concentration of lipids, lipoproteins, and the SAAR score in the subgroups of normolipemic control volunteers

Tab.8 shows the lipid and lipoprotein values obtained and the Score for Anti-Atherogenic Risk (SAAR) in the examined group of 165 control subjects.

In a subgroup of 155 subjects, a non-atherogenic lipoprotein profile phenotype A was identified. In a subgroup of 10 subjects, an atherogenic lipoprotein profile phenotype B was identified. Both lipoprotein phenotypes were confirmed by the Lipoprint LDL method. All examined subjects had normal values of cholesterol and triglycerides. The highest significant difference $(p<0.0001)$ between the subgroup with an atherogenic lipoprotein profile phenotype $B$ and a non-atherogenic lipoprotein profile phenotype A was found in the subfractions LDL 37, i.e., small dense LDL ( $p<0.0001$ ), which represent strongly atherogenic lipoproteins. The SAAR score also showed highly significant differences in the values between the atherogenic and the non-atherogenic subgroup $(\mathrm{p}<0.0001)$. There was a higher concentration of triglycerides $(p<0.001)$ in the atherogenic subgroup. LDL1 was higher in the non-atherogenic subgroup $(p<0.01)$ and LDL2 was higher in the atherogenic subgroup.

\section{Discussion}

The identification of atherogenic and non-atherogenic lipoproteins in the plasma lipoprotein spectrum represents a deeper analysis of lipoprotein parameters than a routine analysis of plasma cholesterol, triglycerides, or lipoproteins like LDL, HDL, and VLDL. These lipid parameters only provide limited information about the percentage of subjects in the general population (general group of subjects) who are at-risk for a sudden attack for cardiovascular or cerebral-vascular event. The 41 percent of the subjects from our large population of 950 individuals, who were identified by this analytical method, would not otherwise have been identified, confirming the value of this information for physicians (Tab.2) know that, based on mortality statistics, approximately 50 percent of deaths are caused by cardiovascular events. It may be that this 41 percent represents a major part of the 50 percent of deaths attributable to a cardiovascular cause, and the individuals with atherogenic dyslipidemia are surely at risk for a sudden cardiovascular event. Thus these individuals could be target for close monitoring, have a follow-up examination, and the optimal treatment could be recommended. 
In addition, the identification of six percent of normolipidemic young healthy individuals with an atherogenic lipoprotein profile among clinically healthy volunteers questions our knowledge and generally accepted belief that normolipidemia, 'per se', represents an optimal health lipid constellation (Tab.8). An atherogenic normolipidemia in the lipoprotein profile of our clinically healthy subjects represents a new phenomenon. These individuals are also at risk for the development of premature cardiovascular ischemic disease and should undergo close medical follow-up. If these individuals receive no preventive antiatherothrombotic measures, the manifestation of cardiovascular ischemic diseases is certain later in life.

The findings of hypercholesterolemia in clinically healthy subjects, without clinically apparent signs of cardiovascular disease or laboratory confirmation of cardiovascular disease, and with a negative history for the occurence of cardiovascular events, stimulated an active search for hypercholesterolemic indviduals and the initiation of a medical examination of these subjects.

For the identification of the hypercholesterolemic individuals with a non-atherogenic lipoprotein profile, a new innovative electrophoretic method for the analysis of plasma lipoproteins on polyacrylamide gel (PAG) was used (Hoefner et.al 2001). The method can analyze the total lipoprotein spectrum of examined subjects, identify an atherogenic/nonatherogenic lipoprotein profile, and quantify the atherogenic lipoprotein subpopulations in plasma, including strongly atherogenic LDL subpopulations, i.e., the small dense LDL, which form the subfractions LDL 3-7. In the absence of atherogenic lipoproteins, or when the atherogenic lipoproteins form a minor part of the whole lipoprotein spectrum, a nonatherogenic lipoprotein profile exists.

The identification of a non-atherogenic hypercholesterolemia offers new information, which suggests a re-evaluation of the belief that the whole LDL family is an atherogenic lipoprotein part of the plasma lipoprotein spectrum. Our results confirme the results of several previous research studies. They show that only a part of the LDL is atherogenic. Atherogenic are small dense LDL, subfraction of LDL, which are associated with the premature development of ischemic cardiovascular diseases. In contrast, LDL1 and LDL2, even in higher concentrations in plasma, do not represent a high cardiovascular risk. Also negative cardiological examination with normal results: only milde signs of clinically irrelevant aortic valve sclerosis, support and confirm the non-atherogenicity of large 'buoyant' LDL subfractions in the individuals with hyperbetalipoproteinemia LDL1,2. Fig.1 - 4. Based on these laboratory results and medical findings, the medical approach to these hypercholesterolemic individuals needs to be revised. The intensive hypolipidemic treatment should not be recommended, and the question also remains, whether any treatment at all, in cases of non-atherogenic hypercholesterolemia, in general, is a reasonable clinical decision. The reduction of total LDL-cholesterol as a target for hypolipidemic treatment for prevention of atherogenesis and atherothrombosis seems to be no longer necessary. 


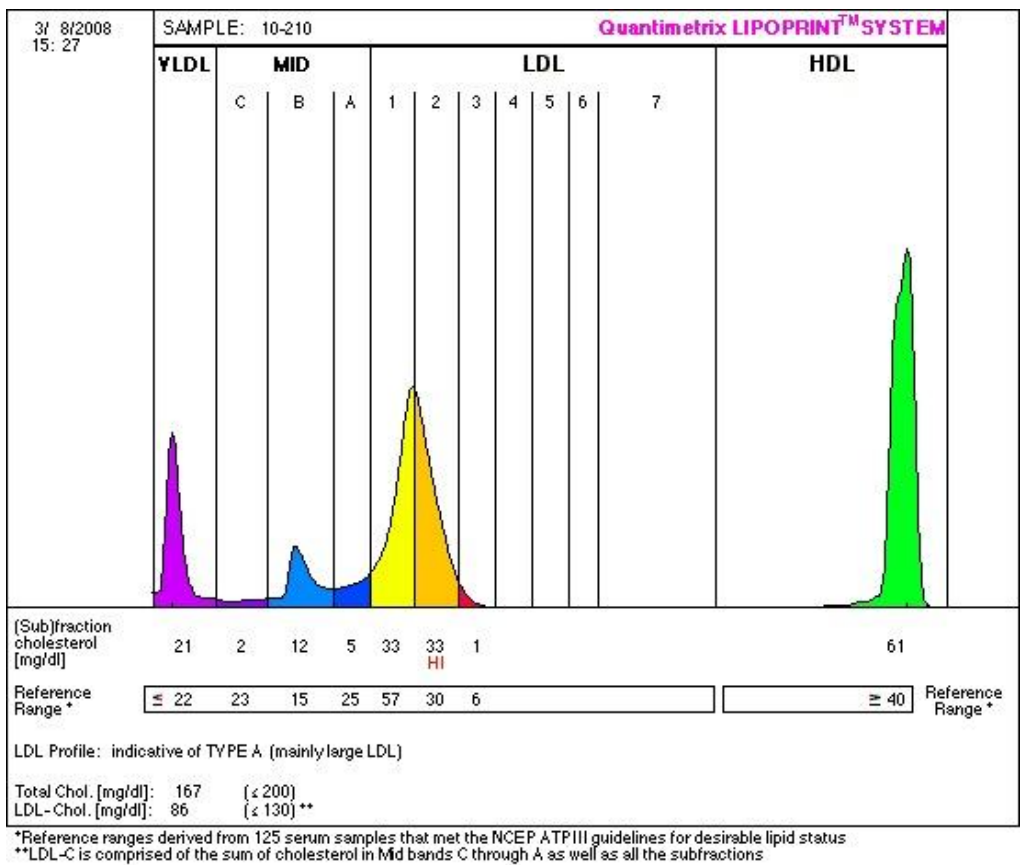

Figure 1. Non-atherogenic normolipidemia

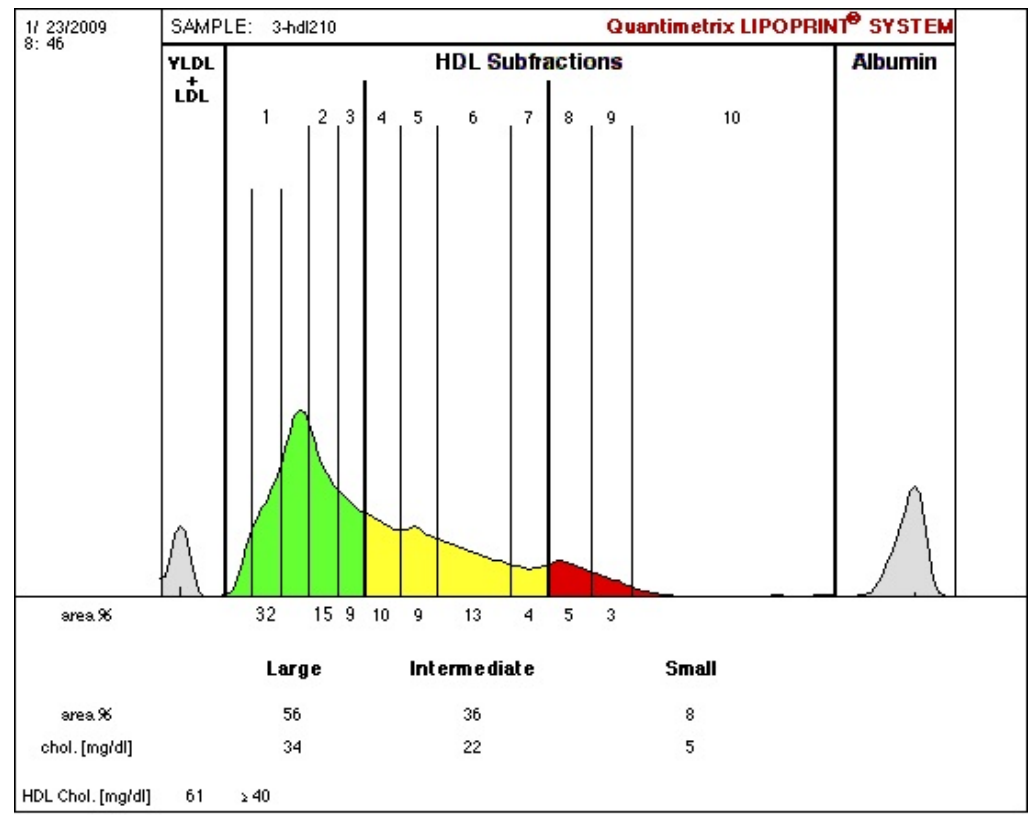

Figure 2. Non-atherogenic normolipidemia HDL subfractions 


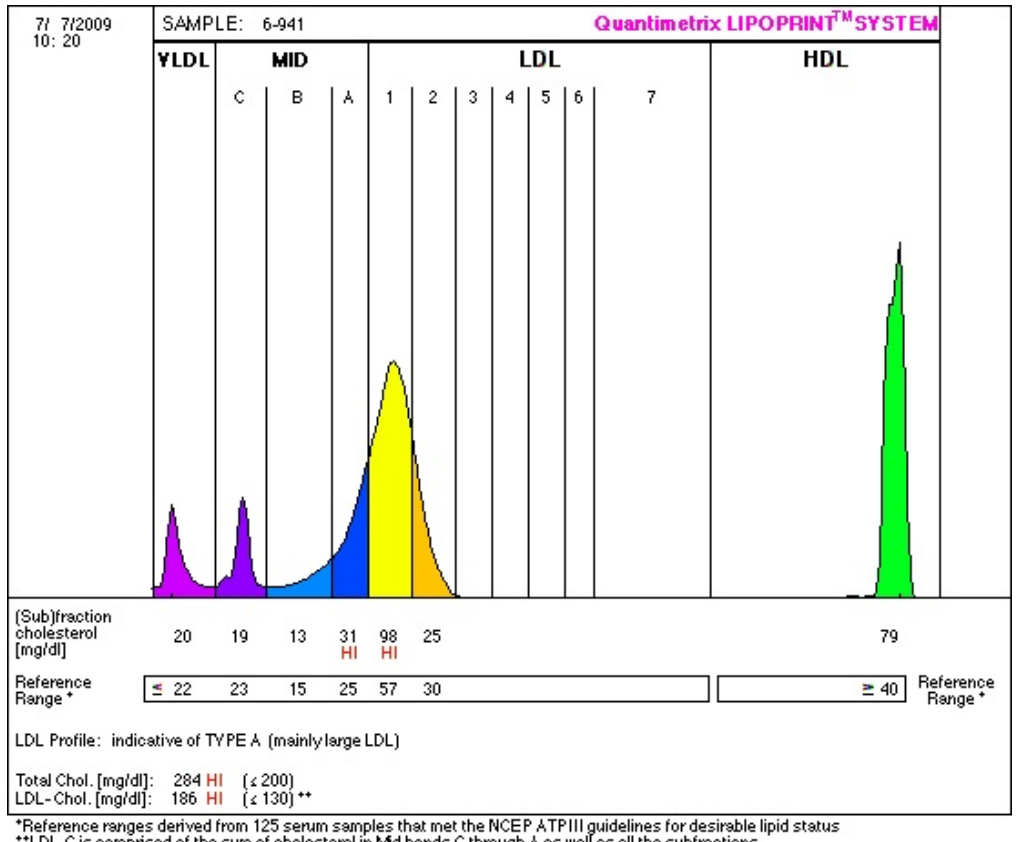

${ }^{+}$Reference ranges derived from 125 serum samples that met the NCEP ATPIII quidelines for desirable lipid statu

Figure 3. Non-atherogenic hyperbetalipoproteinemia LDL1,2

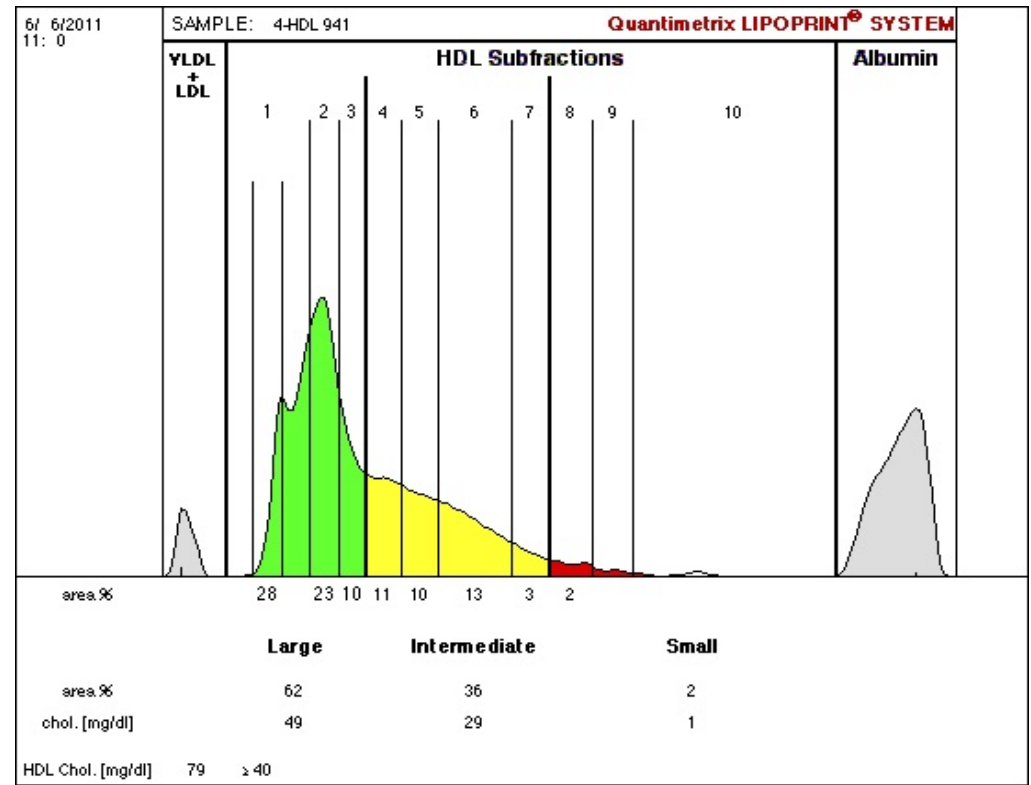

Figure 4. Non-atherogenic hyperbetalipoproteinemiaLDL1,2 HDL subfractions 


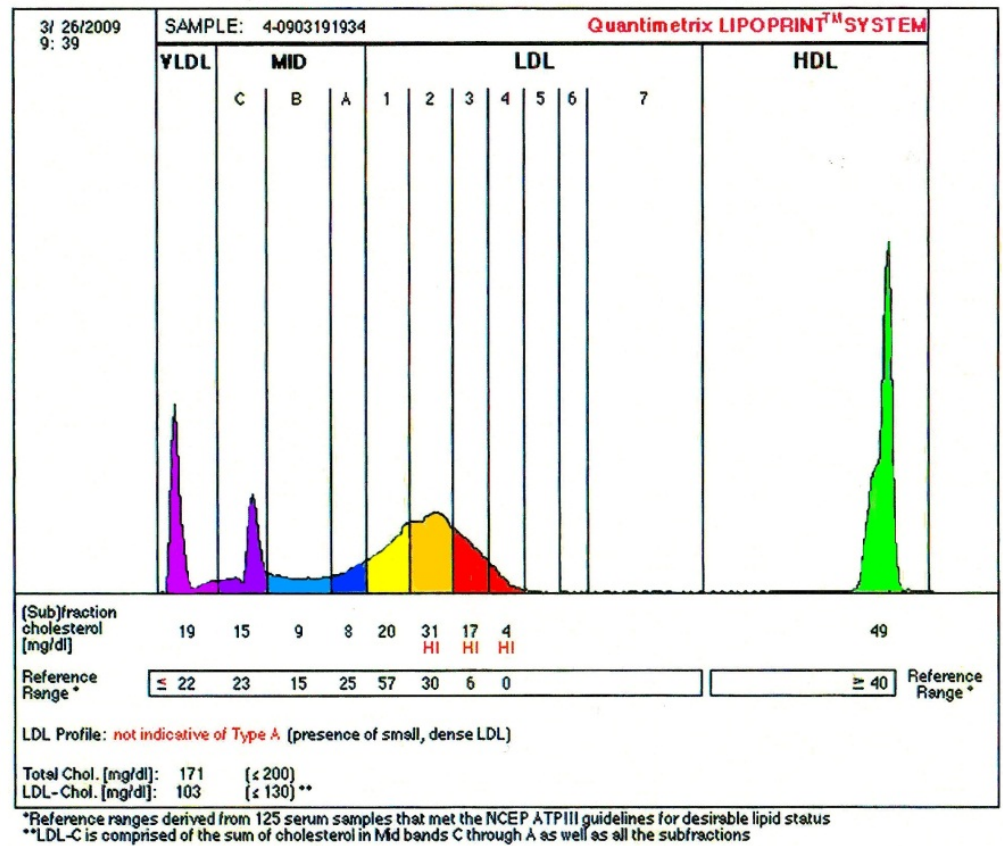

Figure 5. Atherogenic normolipidemia

LDL represent a lipoprotein family created by several LDL subfractions with different characteristics and different role in the intermediary metabolism and in the atherothrombogenesis. LDL1 and LDL2 subfractions are important physiological major conveyors of cholesterol in plasma. These subfractions are an important source for the biosynthesis of highly physiologically effective drugs and structures in the body (steroid hormones, bile acids, vitamin D3, membranes of cells and of subcellular structures). Lowering of the concentration of LDL1 and LDL2 by using a non-specific hypolipidemic treatment has a negative effect on several physiological processes, which create the optimal maintenance of healthy equilibrium in the body. LDL1 and LDL2 seem to be a not atherogenic part of LDL. The non-specific lowering of total cholesterol reduces in the first step the concentration of cholesterol in LDL1, LDL2 subfractions. A protective part of LDL (LDL1, LDL2) is removed and the strong atherogenic small dense LDL persist.

The non-specific hypolipidemic treatment does not form a non-atherogenic lipoprotein constellation. On the contrary, along with the impairment of endocrine steroid synthesis in the body, with an unjustified hypolipidemic treatment approach, the atherogenicity of the plasma will be increased. Figure $6-8$ shows a Lipoprint LDL picture of atherogenic normolipidemia obtained frequently after hypolipidemic treatment of atherogenic hypercholesterolemia. 


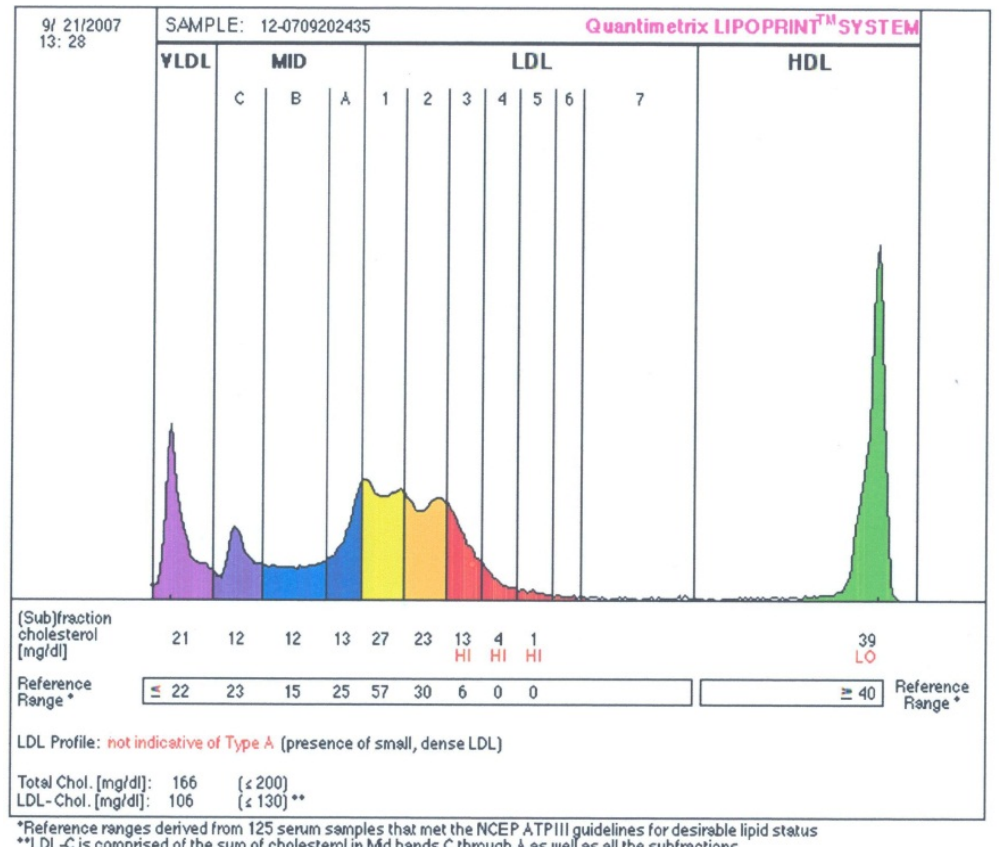

Figure 6. Atherogenic normolipidemia obtained frequently after hypolipidemic treatment of atherogenic hypercholesterolemia

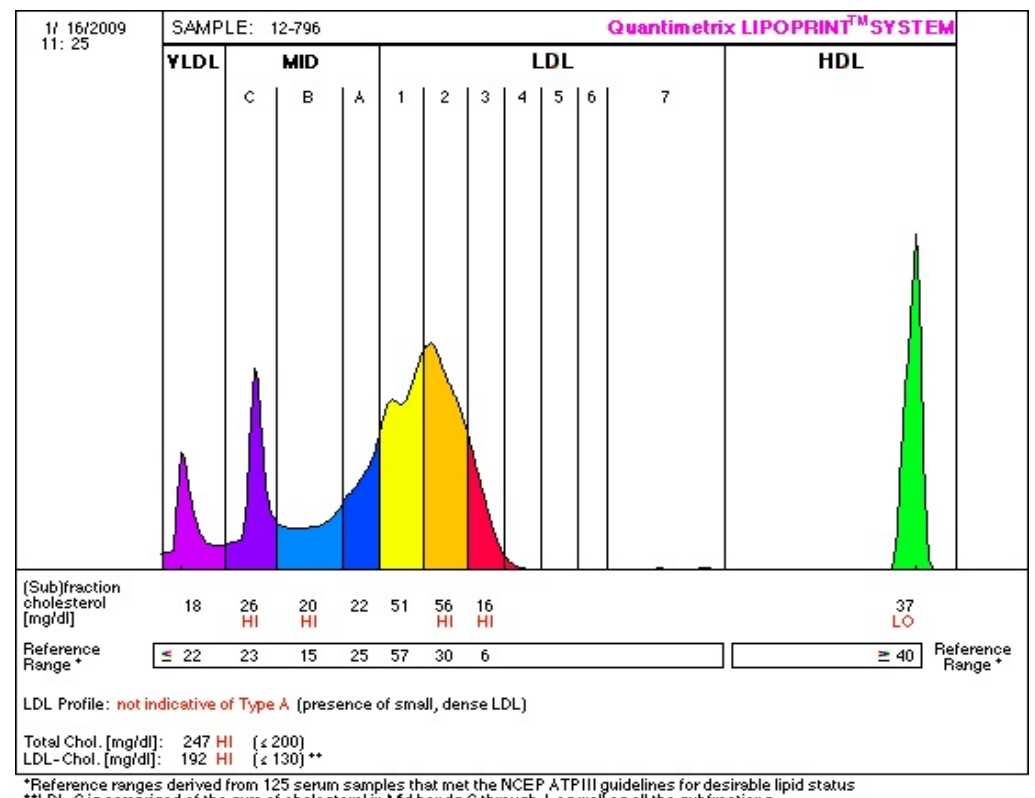

+Reference ranges derived from 125 serum samples that met the NCEP ATPIII guidelines for desirable lipid status

Figure 7. Atherogenic hypercholesterolemia 


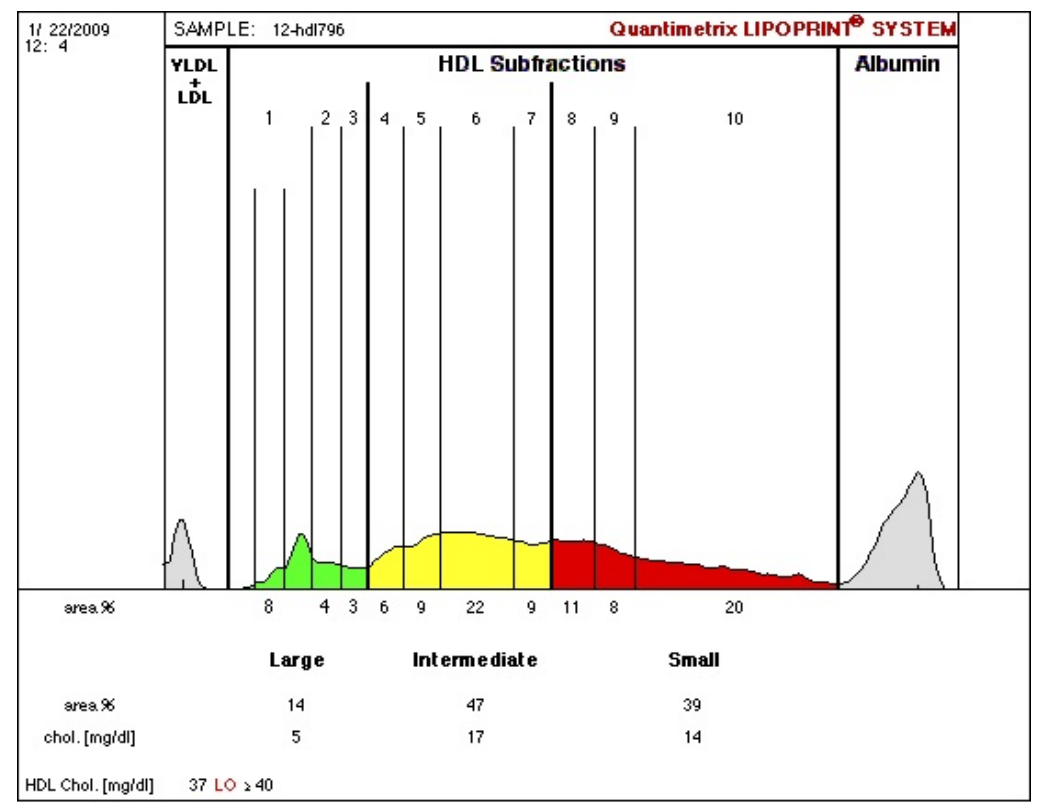

Figure 8. Atherogenic hypercholesterolemia HDL subfractions

In our study a group of individuals with hypercholesterolemia was divided into two subgoups: younger and older subjects (Tab.3-6). The reason was to differentiate the influence of the age factor on the lipoprotein constellation and on the quality of the vascular wall, especially in the group with older subjects. The quality of the arteries was evaluated by medical examination. Tested individuals were examined, including physical examination, blood pressure, and ECG examination, a bicycle stress test, echocardiography, and duplex ultrasound examination of the carotid arteries. The medical results confirmed that the vessel wall was not seriously impaired, not even in older subjects with hypercholesterolemia, which is why a hyper-betalipoproteinemiaLDL1,2 does not represent a serious cardiovascular risk for individuals with this type of hypercholesterolemia.

The results of HDL subclass analysis (Lipoprint HDL System (Morais et al. 2003) in individuals with a non-atherogenic hyperbetalipoproteinemia LDL1 confirm a supposition of low atherogenicity in hyperberalipoproteinemia LDL1,2 (Tab.7), The lipoprotein profile of HDL typically contains a predominance of HDL large and HDL intermediate subclasses, which confer a protective, anti-atherogenic effect on the vessel wall (Morais 2005, Muniz \& Morais 2005 Oravec et al. 2011c). The small HDL subclass with atherogenic characteristics was present in the lipoprotein profile in low concentrations only, compared to the control group of healthy volunteers. Fig. $3-4$. 
The major findings can be summarized as follows:

1. In examined subjects with hypercholesterolemia, a non-atherogenic lipoprotein profile, phenotype A was confirmed with a high concentration of LDL1 and LDL2 subfractions. In particular, the LDL1 subfraction was nearly double that of the LDL1 of the control group, and, in some individual cases, three times that of the control group average (Oravec et al. 2011b).

2. The lipoprotein electrophoresis confirmed only a trace concentration of LDL3-7 subpopulations (1mg LDL 3-7 cholesterol/dl, i.e., $0.0256 \mathrm{mmol} / \mathrm{l})$. In the overwhelming majority of subjects $(60 \%)$ indeed, there was an absence of the atherogenic LDL 3-7 in the lipoprotein profile of these subjects. (Plasma lipoprotein profiles for patients with confirmed cardiovascular disease are generally characterized by a high concentration of small dense LDL) (Kwiterovich 2000, Maslowska 2005, Oravec 2010, Oravec et al. 2010a, 2010b, Oravec et al. 2011a).

3. The concentration of HDL was significantly increased $(\mathrm{p}<0.0001)$ compared to the control group, with an overwhelming majority of the non-atherogenic HDL subpopulations, HDL large and HDL intermediate. The concentration of small dense HDL was not increased (Tab.7), Fig 1-4. Small dense HDL form an atherogenic part of the HDL lipoprotein spectrum, and their higher plasma concentration corelates with the development of cardiovascular diseases (Luc et al. 2002, St Pierre et al. 2005, Morais 2005, Muniz \& Morais 2005, Oravec et al. 2011d), Fig.7,8. The structural representation of HDL subpopulations confirmed a non-atherogenic type of lipoprotein profiles in our examined group of hypercholesterolemic subjects.

4. The examined individuals, despite increased total cholesterol and LDL cholesterol values, were healthy, without apparent clinical signs of cardiovascular disease (angina pectoris, cardiac insufficiency, myocardial infarction, or other survived cardiovascular events). There is evidence that an optimal anti-atherogenic LDL profile (see the lipoprotein results) could actually have a vasoprotective effect in tested hypercholesterolemic individuals. Based on the present results, a further, more extensive study will continue to evaluate the Lipoprint electrophoretic method as a standard method for the diagnosis of cardiovascular risk, along with the standard tests now used (ECG examination, bicycle stress test, echocardiography, and duplex ultrasound examination of the carotid arteries).

5. The newly introduced SAAR, a ratio of non-atherogenic/atherogenic lipoproteins, also confirmed a non-atherogenic lipoprotein constellation in the plasma of hypercholesterolemic individuals (Oravec 2007a).

Based on the results of examined individuals with hypercholesterolemia, these conclusions can be drawn:

1. LDL1 and LDL2 do not fulfill the criteria of atherogenicity for lipoprotein entities that is usually ascribed to LDL lipoproteins.

2. LDL1 and LDL2 subfractons in hypercholesterolemic indidviduals, in our study group, created a non-atherogenic hypercholesterolemia - a non-atherogenic hyperbetalipo- 
proteinemia LDL1,2 without the presence of atherogenic small dense LDL (or with traces only) that are typically associated with a high concentration of cardiovascular protective HDL subfractions in the plasma lipoprotein spectrum.

We report the existence of a newly described type of hypercholesterolemia, a nonatherogenic hyperbetalipoproteinemia LDL 1,2, characterized by a minimal onset of cardiovascular complications, even in those individuals who are not treated with hypolipidemic therapy.

The hypercholesterolemic subjects of the study group are still undergoing follow-up examinations.

\subsection{Atherogenic normolipidemia}

Generally, a normolipidemia is interpreted as an equilibrated state of lipoprotein metabolism, characterized by total cholesterol and triglyceride values within reference ranges. We know from clinical experience that patients with normolipidemia are better protected from development of cardiovascular diseases and degenerative vessel changes, a source of cardio-vascular disease.

In normolipidemia, of the goal is to create a non-atherogenic lipoprotein profile and to lower or eliminate the risk of atherosclerosis development and prevent the rise of an acute cardiovascular event. However, the existence of an atherogenic normolipidemia disproves the theory that normolipidemia provides protection against the development of atherosclerotic vessel impairment. A premature atherosclerosis development can be found even in young people, adolescents with the high risk (Backers 2005; Rizzo \& Berneis 2006).

An atherogenic lipoprotein profile is characterized by the rich presence of atherogenic lipoproteins, very low density lipoprotein (VLDL), intermediate density lipoproteins (IDL1, IDL2), and especially, by the presence of small dense low-density lipoproteins (sdLDL), which form LDL 3-7 subfractions, and which are strongly atherogenic (Lamarche et al. 1997; Gardner et al. 1996; Rajman et al. 1996; Halle et al. 1998, Austin et al. 1994).

An analysis of the lipoprotein profile by the Lipoprint LDL system reveals a new lipoprotein composition in lipoprotein profile and focuses authors on a new clinical-diagnostic phenomenon: an atherogenic normolipidemia. Compared to the well known atherogenic dyslipidemia, or atherogenic hyperlipoproteinemia, this new atherogenic normolipidemia (Oravec et al. 2010; Oravec et al. 2011d) is not identifiable by common biochemical diagnostic analysis.

This phenomenon represents a serious cardiovascular risk for individuals with this profile, and these individuals at high cardiovascular risk are not currently identified, diagnosed, medically registered, or treated. The presence of an atherogenic normolipidemia enlarges the portion of the population at increased risk for a cardiovascular event, however these individuals at risk do not participate on the protective measures of primary cardiovascular prevention. Fig.5. Medical community does not know till now, that the individuals with an atherogenic normolipimia are 
at-risk individuals for the development of premature ischemic cardiovascular diseases. Identification of the type of lipoprotein profile (atherogenic vs. non-atherogenic) by this innovative electrophoretic method for lipoprotein analysis in plasma represents a beneficial contribution to actual lipid diagnostics. This system provides the analysis of lipoprotein parameters but also offers new interpretation for lipoprotein profiles, including an actual framework of the practising scheme for diagnostics and treatment of dyslipidemias.

The Score of Anti-Atherogenic risk SAAR, newly introduced parameter, a ratio of nonatherogenic/atherogenic lipoproteins, also confirmes atherogenic lipoprotein constellation and determines the degree of the atherogenic risk of subjects with atherogenic normolipidemia ( Oravec 2007a; Oravec 2007b; Oravec 2010).

\section{Summary}

A new method of electrophoretic lipoprotein separation on polyacrylamide gel (PAG)using the Lipoprint LDL System can quantify non-atherogenic and atherogenic plasma lipoproteins, including small dense LDL, i.e. strong atherogenic lipoprotein subpopulations.

With respect to the predominance of a non-atherogenic or atherogenic lipoproteins in thewhole lipoprotein profile, this method distinguishes a non-atherogenic lipoprotein profilephenotype A from an atherogenic lipoprotein profile phenotype B.

The contribution of this method is to confirm the existence of a non-atherogenic type of hyper-betalipoproteinaemia and the existence of normolipidemia with atherogenic lipoprotein profile, along with the common and well-known atherogenic hyperlipoproteinemia and non-atherogenic normolipidemia.

According to our preliminary analysis of a normolipidemic population, an atherogenic lipoprotein profile was revealed in $6 \%$ of normolipidemic young healthy individuals.

More than $40 \%$ of the examined individuals in the general group of subjects had an atherogenic lipoprotein profile phenotype B. These people represent an at-risk population.

However, the tools by which is possible to identify these individuals at risk for a cardiovascular event are limited.

A non-atherogenic hyperbetalipoproteinemiaLDL1,2 can be identified, which represents approxmately $20 \%$ of examined individuals with hypercholesterolemia and $10 \%$ of individuals in a general group of subjects. HyperbetalipoproteinemiaLDL1,2 is not associated with the premature development of arterial vascular impairment.

\section{Author details}

Stanislav Oravec

$2^{\text {nd }}$ Department of Internal Medicine,

Faculty of Medicine, Comenius University, Bratislava, Slovak Republic 
Johannes Mikl

Department of Cardiology, Hietzing Hospital, Austria

Kristina Gruber

Department of Internal Medicine, Landesklinikum Thermenregion Baden, Austria

Elisabeth Dostal

Krankenanstalten Dr. Dostal, Vienna, Austria

\section{Acknowledgement}

This study was supported by an EU structural research fund Interreg III AT-SR, project code: 1414-02-000-28 in years 2006-2008.

We would like to acknowledge the excellent technical assistance of MTA Barbara Reif, MTA Judith Trettler and MTA Karin Waitz, Krankenanstalten Dr.Dostal, Vienna, Austria and also to acknowledge the excellent technical assistance of MTA Olga Reinoldova, 2nd Department of Internal Medicine, Faculty of Medicine, Comenius University, Bratislava, Slovakia

\section{References}

[1] Goldstein JL, Brown MS. Receptor mediated endocytosis:concepts emerging from the LDL-receptor system. Ann Rew Cell Biol 1985; 1: 1-39

[2] Steinberg D. Lipoproteins and the pathogenesis of atherosclerosis. Circulation 1987; 76: $504-7$

[3] Witztum JL, Steinberg D. Role of oxidized low density lipoprotein in atherosclerosis. J Clin Invest 1991; 84: 1086 - 95

[4] Ross R. The pathogenesis of atherosclerosis - an update. N Engl J Med 1986; 314: 365 374

[5] Canner PL, Berge KG, Wenger NK, Stamler J, Friedman L, Prineas RJ et al. Fifteen year mortality in Coronary Drug Project patients, long term benefit with niacin. J Amer Coll Cardiol 1986; 8: 1245 - 55

[6] Frick MH, Elo O, Haapa K, Heinonen OP, Heinsalmi P, Helo P, Huttunen JK, Kaitaniemi P, Koskinen P, Manninen V et al. Helsinki Heart Study: primary prevention trial with gemfibrozil in middle aged men with dyslipidemia. N Engl J Med 1987; 317: $1237-45$

[7] Kwiterovich PO. Clinical Relevance of the Biochemical, Metabolic and Genetic Factors that influence Low density Lipoprotein Heterogeneity. Am J Card 2002; 90 (Suppl 8A): $30 \mathrm{i}-48 \mathrm{i}$

[8] Kwiterovich PO. Lipoprotein Heterogeneity: Diagnostic and Therapeutic Implications. Am J Card 2002; 90 (Suppl 8A): 1i-10i

[9] Berneis KK, Krauss RM. Metabolic origins and clinical significance of LDL heterogeneity. J Lipid Res. 2002; 43: 1363-79. 
[10] Expert Panel on Detection Evaluation and Treatment of High Blood Cholesterol in Adults. Executive summary of the third report of the National Cholesterol Education Program (NCEP) expert panel of detection, evaluation and treatment of high blood cholesterol in adults (Adult Treatment Panel III). JAMA 2001; 285: 2488 - 97

[11] Backers JM. Effect of Lipid-Lowering Drug Therapy on Small-dense Low-Dense Lipoprotein. Ann Pharmacol 2005; 39: 523 - 26.

[12] Austin MA, King MC, Vranizan KM, Krauss RM. Atherogenic lipoprotein phenotype. A proposed genetic marker for coronary heart disease risk. Circulation 1990; 82: 495-506

[13] Chait A, Brazo RL, Tribble DL, Krauss RM. Susceptibility of small, low- density lipoproteins to oxidative modification in subjects with the atherogenic lipoprotein phenotype, pattern B. Amer J Med 1993; 94: 350-6

[14] Van J, Pan J, Charles MA, Krauss R, Wong N, Wu X. Atherogenic lipid phenotype in a general group of subjects. Arch Pathol Lab Medicine 2007; 131: 1679 - 85

[15] Castelli WP. Cholesterol and lipids in the risk of coronary artery disease - The Framingham Heart Study. Can J Cardiol 1988; (Suppl A): 5A-10A.

[16] Castelli WP. Epidemiology of triglycerides; a view from Framingham. Am J Cardiol 1992; 70: 43-49

[17] Castelli WP. The new pathophysiology of coronary artery disease. Am J Cardiol 1998; 82: (Suppl 2): 60-85

[18] Nicholls S, Lundmann P (2004). The emerging role of lipoproteins in atherogenesis: beyond LDL cholesterol. Semin Vasc Med 2004; 4: 187-195

[19] Rizzo M, Berneis K. Low density lipoprotein size and cardiovascular prevention. Europ J Int Med 2006; 17: 77 - 80.

[20] Shoji T, Hatsuda S, Tsuchikura S, Shinohara K, Komoto E, Kovama H, Emoto M, Nishizhawa Y. Small dense low-density lipoprotein cholesterol concentration and carotid atherosclerosis. Atherosclerosis 2009; 202: 582 - 588.

[21] Zhao ChX, Cui YH, Fan Q, Wang PH, Hui R, Cianflone K, Wang DW. Small Dense Low-Density Lipoproteins and Associated Risk Factors in Patients with Stroke. Cerebrovasc Dis 2009; 27: 99-104.

[22] Rainwater DL, Moore PH jr, Shelledy WR, Dyer TD, Slifer SH. Characterization of a composite gradient gel for the electrophoretic separation of lipoproteins. J Lipid Res 1997; 38: 1261-1266

[23] Alabakovska SB, Todorova BB, Labudovic DD, Tosheska KN. Gradient gel electrophoretic separation of LDL and HDL subclasses on BioRad Mini Protean II and size phenotyping in healthy Macedonians. Clin Chim Acta 2002; 317: 119-123.

[24] Otvos JD, Jeyarajah EJ, Bennet SW, Krauss RM.Development of a proton nuclear magnetic resonance spectroscopic method for determining plasma protein concentrations and subspecies distribution from a single, rapid measurement. Clin Chem 1992; 38: 1632- 38

[25] Hoefner DM, Hodel SD, O'Brien JF, Branum EL, Sun D, Meissner I, McConnell JP. Development of a rapid quantitative method for LDL subfraction with use of the Quantimetrix Lipoprint LDL system. Clin Chem 2001; 472: 266-274. 
[26] Lamarche B, Lemieux I, Despres JP. The small, dense LDL phenotype and the risk of coronary heart disease: epidemiology, patho-physiology and therapeutic aspects. Diabetes Metab 1999; 25: 199-211

[27] Packard CJ. Triacylglycerol-rich lipoproteins and the generation of small dense lowdensity lipoprotein. Biochem Soc Transactions 2003; 31: 1066 - 69

[28] Carmena R, Duriez P, Fruchart JC. Atherogenic lipoprotein particles in atherosclerosis. Circulation 2004; 109: III2-III7

[29] Oravec S. Nová laboratórno-medicínska pomoc vdiagnostike dyslipoproteinemií a kardiovaskulárnych ochorení: Identifikácia LDL podskupín. Med Milit Slov 2006a; 8: 28-32.

[30] Oravec S. Identifikácia subpopulácií LDL triedy -Aktuálny prínos v diagnostike porúch metabolizmu lipoproteínov a ochorení kardiovaskulárneho systému. Med Milit Slov 2006b; 8: 32-34.

[31] Oravec S. Nové perspektívy v diagnostike porúch metabolizmu lipoproteínov - prínos v interpretácii výsledkov. Med Milit Slov 2007a; 9: 42-45

[32] Oravec S. Nové možnosti posúdenia kardiovaskulárneho rizika u pacientov s obezitou a metabolickými ochoreniami. Med Milit Slov 2007b; 9: 46-49.

[33] Morais J, Neyer G, Muniz N. Measurement and Distribution of HDL subclasses with the new Lipoprint ${ }^{\circledR}$ HDL Method (pdf format). Presented at AACC, Philadelphia, PA , June 2003

[34] Morais J. Quantimetrix shows that all HDL subfractions may not protect against heart disease. AACC international congress of Clinical Chemistry, Orlando, FL, June 2005

[35] Muniz N, Morais J. Coronary heart disease. High density lipoprotein subclasses associated with heart disease. Medical Letter on the CDL and FDA, July 31

[36] Maslowska M, Wang HW, Cianflone K. Novel roles for acylation stimulatory protein/C3ades Atg: a review of recent in vitro and in vivo evidence. Vitam Horm 2005; 70: 309-32

[37] Kwiterovich PO jr. The metabolic pathways of HDL,LDL and triglycerides. A current review. Am J Card 2000; 86 (Suppl 1): 5-10

[38] Oravec S. Den drohenden Herztod erkennen- und vermeiden. Der Mediziner 2010; 4: 6-7

[39] Oravec S, Dukát A, Gavorník P, Caprnda M, Kucera M. Lipoproteínový profil séra pri novozistenej arteriálnej hypertenzii. Úloha aterogénnych lipoproteínov v patogenéze ochorenia. Vnitr Lek 2010a; 56: 967-971.

[40] Oravec S., Dukát A., Gavorník P., Čaprnda M, Reinoldová O.Zmeny v lipoproteínovom spektre pri končatinovo-cievnej ischemickej chorobe.Vnitř. Lék 2010b; 56(6): 620-623

[41] Oravec S, Dukat A, Gavornok P, Caprnda M, Kucera M, Ocadlik I. Contribution of the atherogenic lipoprotein profile to the development of arterial hypertension. Brat Lek Listy 2011a; 112: 4-7

[42] 42) Luc G, Bard J-M, Ferriéres J, Evans A, Amouyel P, Arveiler D, Fruchart J-Ch, Ducimetière P, Prime Study Group. Value of HDL-cholesterol, apolipoprotein A-I, Lipoprotein A-I, Lipoprotein A-I/A-II in prediction of coronary heart disease . The Prime Study. Arterioscler Thromb Vasc Biol. 2002; 22: 1155- 61

[43] St-Pierre AC, Cantin B, Daganais GR, Mauriege P, Bernard PM, Despres JP, Lamarche B. Low density lipoprotein subfractions and the long-term risk of ischemic heart disease in 
men: 13-year follow-up data from the Quebec Cardiovascular Study. Arterioscler Thromb Vasc Biol. 2005; 25: 553-559

[44] Fruchart JC, Sacks FM, Hermans MP et al. The residual risk reduction initiative: a call to action to reduce residual vascular risk in dyslipidaemic patients. Diabetes Vasc Res 2008; 5: 319-335

[45] Chun Xia Zhao, Ying Hua Cui, Qiao Fan, Pei Hua Wang, Ruitai Hui, Cianflone K, Dao Wen Wang. Small Dense Low-Density Lipoproteins and Associated Risk Factors in Patients with Stroke. Cerebrovasc Dis 2009; 27: 99-104

[46] Haffner SM. The metabolic syndrome: inflammation, diabetes mellitus and cardiovascular disease. Am J Cardiol 2006; 97: 3A-11A

[47] Lamarche B, Tchernof A, Moorjani S, Cantin B, Dagenais GR, Lupien PJ, Despres JP. Small dense LDL lipoprotein particles as a predictor of the risk of ischemic heart disease in men. Prospective results from the Quebec Cardiovascular Study. Circulation 1997; 95: 69-75

[48] Gardner CD, Fortman SP, Krauss RM. Association of small low-density lipoprotein particles with the incidence of coronary artery disease in men and women. JAMA 1996; 276: 875-881

[49] Rajman I, Kendall MJ, Cramb R, Holder RL, Salih M, Gammage MD. Investigation of low density lipoprotein subfractions as a coronary risk factor in normotriglyceridaemic men. Atherosclerosis 1996; 125: 231-42

[50] Halle M, Berg A, Baumstark MW, Keul L. LDL-Subfraktionen und koronare Herzerkrankung - Eine Übersicht. Zeitschrift Kardiol 1998; 87: 317-30

[51] Austin MA, Hokanson JE, Brunzell JD. Characterization of low-density lipoprotein subclasses: methodologic approaches and clinical relevance. Curr.Opinion Lipidol 1994; 5: 395-403

[52] Oravec S, Gruber K, Dostal E, Mikl J. Hyper-betalipoproteinenmia LDL1,2: a newly identified non-atherogenic hypercholesterolemia in a group of hypercholesterolemic subjects. Neureoendocrinol Lett 2011b; 32: 322-327

[53] Oravec S, Dostal E, Dukat A, Gavorník P, Kucera M, Gruber K. HDL subfractions analysis: A new laboratory diagnostic assay for patients with cardiovascular diseases and dyslipoproteinemia. Neuroendocrinol Lett 2011c; 32: 502-509

[54] Oravec S, Dukat A, Gavorník P, Lovásová Z, Gruber K. Atherogenic normolipidemia a new phenomenon in the lipoprotein of clinically healthy subjects. Neuroendocrinol Lett 2011d; 32:317-321 